\title{
HEMATITE. PROCESSING AND APPLICATIONS
}

\section{Mircea DOBRESCU, Marius VASILESCU}

Politehnica University of Bucharest, Romania

e-mail: vmarius_sim_pub@yahoo.com

\begin{abstract}
In the paper are shown the history, processing and applications of hematite.

Hematite is an oxide of iron having the composition $\mathrm{Fe}_{2} \mathrm{O}_{3}$. Pure hematite, also called "red ore" contains $70 \% \mathrm{Fe}$.

Manufacturing processes for steel are made in furnaces (open hearth, Bessemer processes, oxygen furnace, electric arc furnaces).

Hematite is used both as an ore of iron and as an industrial mineral in order to produce intermediate products such as: - Sinter; - Pellets; - Pig iron; - Malleable cast iron; - High duty cast iron; - Wrought iron; - Directly reduced iron; - Iron carbide; - Steel.
\end{abstract}

KEYWORDS: hematite, processing, applications

\section{Introduction}

Hematite is an oxide of iron having the composition $\mathrm{Fe}_{2} \mathrm{O}_{3}$. Pure hematite, also called "red ore" (in fact, the name hematite comes from the word "hemo" meaning blood), contains 70\% Fe [1]. Almost pure hematite occurs on the edge of Cockatoo island in Western Australia. But generally, it contains various other constituents, namely $\mathrm{SiO}_{2}, \mathrm{Al}_{2} \mathrm{O}_{3}, \mathrm{P}, \mathrm{S}$, $\mathrm{TiO}_{2}, \mathrm{Zn}, \mathrm{Cu}, \mathrm{As}, \mathrm{Sn}, \mathrm{Cr}$ and $\mathrm{Ni}$ [2]. Out of these, the first four are common in Indian hematite.

In nature, its structure varies from compact specular and columnar to foliated (micaceous hematite). When mixed with clay or sand, it is called argillaceous hematite or clay iron stone. The coarsegrained variety with brilliant metallurgical luster is known as "specular iron ore", [3]. Hematite is the most widely distributed and mined iron ore. Mining is generally by open cast method.

The only exceptions are a few underground mines in USA and the Hiparsa mine in Argentina, which was mined by underground method until 1993, and plans were afoot in 2004 to revive it. Kryvy Rich of Ukraine and Carajas of Brazil are regarded as the two largest deposits of the world. As in 2004, the estimated reserves in the former were 24 billion tonnes and, in the latter, 18 billion tonnes $(66 \% \mathrm{Fe})$.

In India, hematite occurs mainly as banded formations (e.g., banded hematite quartzite or BHQ) belonging to the Precambrian age, and is fairly widely distributed in the states of Jharkhand, Orissa, Chhattisgarh, Kamataka, Goa and Maharashtra. Iron ore bodies occur as pockets at the top of these formations enriched in iron due to weathering and leaching out of silica [4]. The hematite iron ore of India is generally high-alumina and high-silica at places containing up to $6 \% \mathrm{Al}_{2} \mathrm{O}_{3}$ and up to $8 \% \mathrm{SiO}_{2}$.

The other main impurity is phosphorus (up to $0.1 \%$ ). The ore occurs in both "lumps" and "fines" forms. In some places of eastern India, very high grade ultra-fine blue dust occurs in significant quantities.

In the evolution of civilization, the year 1800 $\mathrm{BC}$ is an important milestone. Right since the paleolithic age through the Neolithic age, copper age and thereafter bronze age till $1800 \mathrm{BC}$, the entire period is referred to as "old world". The oldest evidence of manufacture and use of iron dates back to the year $1800 \mathrm{BC}$, and this is regarded as the beginning of "iron age" and what is referred to as the "new world".

Invention of iron set off a chain of technological revolutions which has been continuing ever since. But the use of hematite is believed to be known to man long before the invention of iron metal. In rock paintings discovered by archaeologists in Mirzapur district of Uttar Pradesh, India and believed to be 8000 years old, various colours have been observed. It has been concluded that among different colours, different shades of red were obtained from hematite. In the beginning of iron age, it is believed that some pure iron materials were accidentally found and such iron was used during the times of Pharaohs in Egypt.

Most probably the iron was sourced to some meteorites, which used to be referred to as "star metal" or "stones from heaven" or "gift of the gods". 
Manufacturing of iron is believed to begin in around 1200 BC. Steel making technology more or less coincided with the beginning of Christian era. In the $14^{\text {th }}$ century, large scale operations started with the invention of blast furnace in Great Britain.

Initially, for a couple of hundred years, wood charcoal was used as fuel; but later on, in 1710, coal revolutionized the iron-making technology. Large scale manufacturing of steel became possible only after 1856, when Bessemer invented his conversion process.

In USA, although the use of iron ore was known in 1608, organized iron industry began in 1844 after the Lake Superior deposits were discovered. In India, iron-made weapons were mentioned in mythology, but the first recorded history regarding the use of iron-made weapons dates back to the time of Alexander's invasion (326 BC). Iron casting technology was not known in those days, and canons and guns were mostly made by forging wrought iron.

The iron pillar in New Delhi (310 AD) was an excellent example of forged wrought iron. The technology for melting and shaping of "wootz", a kind of ultra-high carbon steel containing $1.5 \% \mathrm{C}$ also known as "Damascus steel" or "Ukku" or "Bulat" or "Ondanique", which used to be exported to Damascus from India for making "Damascus swords", was known in India as early as $300 \mathrm{BC}$. The indigenous iron and steel industries, though small scale and unorganized, were widely spread throughout India during the ancient and Medieval periods. During 1778-1795, some sporadic operations were carried out by M/S Farquhar \& Motte in Birbhum district of Bengal. Their operations were based on local methods, most probably using charcoal, and were eventually abandoned.
The European methods of smelting iron ore were successfully adopted for the first time in 1830, when the India Steel Iron and Chrome Company was established by J. M. Heath and a pig iron plant based on ore from Salem district of Tamil Nadu, was set up in Porto Novo in South Arcot district of Tamil Nadu. These works were taken over in 1883 by Porto Novo Steel \& Iron Co. and the East Indian Iron Co, which expanded the industry by starting additional pig iron plants in UK. But because of bad financial management, the company finally closed down in 1867. During the period 1839-1875, unsuccessful attempts for manufacturing iron using charcoal, were made in Bengal, in Nainital district of present Uttaranchal state and in Indore, Madhya Pradesh.

By 1875, both coal mining and coke manufacturing had commenced in Bengal, and using coke based on coal from Raniganj coal field, pig iron manufacturing was started in Kulti and Hirapur in Bengal by a private company, which was taken over by the government in 1884 and again resold in 1889 to Bengal Iron \&Steel Co. Ltd. (renamed as BengalIron Co. Ltd. in 1919). In that plant, steel was manufactured during a brief period 1903-1905, in an open-heart furnace.

In 1911, Tata Iron \&Steel Co. established its plant in Jamshedpur in present Jharkhand. This was followed by the furnaces of Indian Iron \& Steel Co. at Burnpur in present West Bengal in 1992, which took over the Kulti plant of Bengal Iron Co. Ltd. in 1936. Based on pig iron produced in the Hirapur works, Burn \& Co. started manufacturing steel products at Kolkata in 1937. Meanwhile, in 1933, Mysore Government started a charcoal-based iron plant at Bhadravati in 1993.

Table 1. Hematite production in India

\begin{tabular}{|c|c|}
\hline Years & Hematite production [t] \\
\hline 1900 & 70000 \\
\hline 1940 & 3.00 million \\
\hline 1950 & 3.14 million \\
\hline 1960 & 16.61 million \\
\hline 1970 & 31.37 million \\
\hline 1980 & 41.94 million \\
\hline 1990 & 54.58 million \\
\hline April, 2000 - March, 2001 & 80.59 million \\
\hline April, 2001 - March, 2002 & 96.96 million \\
\hline April, 2004 - March, 2005 & 142.71 million \\
\hline
\end{tabular}

These plants kept on introducing newer and newer technologies and built the foundation of the Indian iron and steel industry before its independence in 1947. After independence, in 1953, the Government of India set up Hindustan Steel Ltd., and three steel plants came up at Rourkela in Orissa, at Bhilai in present Chhattisgarh and at Durgapur in West Bengal. This company was later renamed as Steel Authority of India Ltd. (SAIL), and a few more plants manufacturing steel and special steels at 
Bokaro in present Jharkhand, at Slem in Tamil Nadu and at Chandrapur in Maharashtra were added to it.

By the early $21^{\text {st }}$ century, there were 11 primary iron and steel plants and number of secondary steel plants. The production of pig iron, which was a meagre 12700 tonnes during the 5-year period 18751879 , rose to 1.67 million tonnes of pig iron plus 1.46 million tonnes of steel ingots in 1950, and then to 4.07 million tonnes of pig iron plus 31.63 million tonnes of steel in 2001-02 compared to world steel production of 965 million tonnes during 2003.

History of iron ore (hematite) mining in India is as old as the history of iron and steel production. The recorded history of production of hematite is presented in Table 1.

Contrary to steel, the iron ore production of India compares better to the world production which stood at 1098 million tonnes during 2003.

\section{Criteria of use}

Hematite is used both as an ore of iron and as an industrial mineral. Its typical characteristics that make it suitable for different uses are as follows:

- The chemical composition is ferric oxide $\left(\mathrm{Fe}_{2} \mathrm{O}_{3}\right)$ with the highest degree of oxidation possible. The most important element in it is iron, the theoretical content of which is $70 \% \mathrm{Fe}$. But in nature, chemically pure hematite is difficult to mine economically due to its physical properties, and some residual impurities (e.g., $\mathrm{Al}_{2} \mathrm{O}_{3}, \mathrm{SiO}_{2}$ ) get into the mineral. Because of the highest degree of oxidation, this compound of iron is saturated with oxygen and it is, therefore, easier to reduce (in case of undersaturation, the affinity between iron and oxygen is somewhat strong and it becomes relatively difficult to separate the two elements).

- Physically, pure hematite is a medium hard mineral, its hardness being in the range of 5.5-6.5 in the Mohs scale [5]. But in nature, the economically significant hematites occur near the surface as a result of erosion of silicates. Hence these hematites are softer and also porous, i.e., not very dense or compact even when they are in lumpy form. Besides, they occur also as friable ore prone to breaking into fines during mining and handling.

- It is resistant to corrosion [5].

- It has a high refractive index ranging in values from 2.94-3.22 when in the form of very thin laminae as in the case of micaceous hematite [6]. Refractive index is a measure of the change in direction that oblique light rays undergo when travelling from air to another medium (in this case the hematite laminae) and is expressed with reference to air (refractive index practically 1). Refractive index has some relation to luster.
- Although colour of hematite is dark grey to black, it is blood red when in powder form.

- The micaceous hematite has a mica-like platy structure. It crumbles easily to powder.

\section{Applications}

Hematite is mostly used to produce some intermediate products, and in a lesser degree, some directly usable products. These, as well as the relatively less popular ones are sinter, pellets, pig iron, cast iron, malleable cast iron, high duty cast iron, wrought iron, directly reduced iron, iron carbide and steel.

\subsection{Sinter}

One of the methods to convert iron ore fines is sintering [7]. By application of just enough heat to fuse the corners of the ore particles, they are made to join together to form a lumpy mass.

This product is called "sinter". Sinters are not very compact, having $11-18 \%$ porosity, because some comers of a particle melt, and not the entire particle. But, at the same time, they are tough enough to withstand the stress within a blast furnace. These are good substitutes of natural lumps, and can be blended with the latter in the blast furnace charge.

For optimizing productivity of blast furnaces, the fluxing material i.e. limestone powder $(90 \% 3$ $\mathrm{mm}$ size) is intimately mixed at the sintering stage itself. The limestone adds strength to the sinter if it is distributed uniformly in the matrix. This superfluxing of sinters eliminates the need for raw limestone charge [8]. Coke breeze ( $85 \% 3 \mathrm{~mm}$ size), dolomite mill scales and flue dust fines along with limestone, can also be mixed to make the sinter a completely self-sufficient feed. Sinters are made on rectangular flat tops of cylinders tapering downward to grate bottoms.

\subsection{Pellets}

Very fine particles (size of microns) cannot be sintered as they will fuse altogether. So, they are formed into spherical objects called "pellets", and the process is called palletisation. To the iron ore fines, 0.5-3.0\% bentonite is added as binder [9].

Coke breeze and some flux (limestone) may also be added. The mixture is placed in cones, drums or discs, out of which discs are relatively more flexible with regard to types of ore and they can be controlled better. A disc pelletizer is a rotating inclined flat plate table. The particles gradually coalesce - first into very small pellets, which go on taking more and more 
particles and keep enlarging in size till they attain specified sizes. Water is sprayed as required.

These are called green pellets, and the operation is called "balling". The control is affected by changing the angle $\left(20-80^{\circ}\right)$ and the r.p.m. $(+8)$ of the disc. The green pellets are then heat treated at a temperature of above $1200{ }^{\circ} \mathrm{C}-$ generally around $1315^{\circ} \mathrm{C}$ - in grate kilns, followed by air cooling with a view to obtaining necessary strength.

The quality of pellets usable in the blast furnace is mainly determined by their characteristics of size, crushing and abrasion resistance, reducibility and the free growth and porosity index. The values of the parameters are determined through industrial scale experiments by setting the prerequisite that when using pellets in the blast furnaces, their diameters should be in range $9.5-25.0 \mathrm{~mm}$ and within this range the size fraction $10-15 \mathrm{~mm}$ should represent a minimum of $85 \%$. Values of $6 \%$ for crushing and $5 \%$ for abrasion (drum values i.e., percentage of pellets not able to withstand the stress in a standard rotating drum) are considered acceptable [10].

A reducibility index of $0.7-0.8 \%$ per minute for basic pellets is considered good. A maximum of $14 \%$ free growth index (increase in volume expressed as a percentage of initial volume under test conditions i.e., $1050{ }^{\circ} \mathrm{C}$ for 30 minutes in a $\mathrm{CO}$ blow). Porosity should be between $20 \%$ and $30 \%$. Unlike sinter, even if limestone is added to raw mix for pellets, supplementary limestone addition in blast furnace is necessary [11].

A minimum of $25 \%$ of pellets in the blast furnace charge has been found to have a salutary effect on productivity.

\subsection{Pig iron}

Pig iron is both an intermediate product for steel manufacturing and a material for direct use in casting (cast iron) or fabricating (wrought iron) parts of machines, structures, etc. In old references, pig iron for these different types of uses used to be mentioned as "foundry" and "basic" grades of pig iron.

Nowadays, this classification is no longer used. A special type of low-phosphorus pig iron is used for making "spun pipes". Pig iron is produced in tall blast furnaces into which, conventionally, a charge of lumpy iron ore (either natural lumps or fines converted to this form), limestone, coke and manganese oxide is dripped from the top, and subjected to blasts of air through the sides at the lower zone; and to which some initial heat is applied.

So far as natural lumps are concerned, they are seldom mined in the required grades, and it has now become an established practice to subject them to some preparation or beneficiation. The conventional methods consist of plain water washing and scrubbing, tromelling, wet screening, classification, and jigging or cycloning. But these methods achieve only limited success inasmuch as the ultra-fine grains of $\mathrm{Al}_{2} \mathrm{O}_{3}$ are not eliminated, and also considerable iron values are lost in the slimes.

A specialized method consists in the selective dispersion (flocculation) of aluminous gangue from a dilute slurry system using organic/inorganic additives (e.q., sodium humate, starch, polyacrylamide, phenoland lignite-based polymer additives etc. [12].

The reactions within a blast furnace are very complex. But the essential principle can be explained thus. The carbon of the coke reacts with the oxygen of the air to produce heat and carbon monoxide (CO). The heat melts the charge, and the $\mathrm{CO}$, being unsaturated oxide, combines with the oxygen of the hematite reducing the latter to metallic iron, and generating carbon dioxide $\left(\mathrm{CO}_{2}\right),[12,13]$.

The impurities such as $\mathrm{SiO}_{2}$ and $\mathrm{Al}_{2} \mathrm{O}_{3}$ present in the hematite react with the limestone producing lime-alumina silicates (with heavy metal oxides) called "slag" and a mixture of $\mathrm{CO}, \mathrm{CO}_{2}$ and $\mathrm{NO}_{2}$ that escape as top gas. The molten slag, being lighter than and immiscible in the molten iron metal, floats on the surface of the latter.

The upper layer of the molten slag is tapped out through an outlet at the upper level of the blast furnace, processed depending on its future use and stacked separately where it cools and solidifies. The molten iron of the blast furnace is transferred into the pig bed (sand moulds for ingots) or mobile ladles.

In fact, the name "pig iron" originated in the early days of iron ore reduction when the total output of the blast furnace was sand-cast into masses of iron resembling the shape of a reclining pig. The oldest method of pig-casting in sand beds has now been replaced by pig-casting machines. Pig iron contains $3-4 \% \mathrm{C}$ in general (may be up to $6 \%$ ) besides little quantities of manganese, phosphorus, sulphur and silicon. High carbon content makes it hard and brittle.

Depending on the form in which the carbon occurs within pig iron, it can be either grey pig iron or white pig iron. In grey pig iron, carbon is precipitated in the fractures as graphite flakes; in the white pig iron, it is dissolved as iron carbide. White pig iron is harder and more brittle in comparison to grey pig iron.

Both types of pig iron are the basic raw materials for making downstream products such as cast iron, wrought iron, spheroidal graphite iron and steel. The differences amongst these products lie mainly in the carbon content.

\subsection{Cast iron}

Pig iron ingot or cast-iron scrap is remelted in cupola furnaces, carbon and other elements are added 
according to the required specification, and cast in foundry moulds in the desired shapes and sizes as per the end products.

The cast iron made from white pig iron is called "white cast iron"; and that from grey pig iron, "grey cast iron". White cast iron is used where the components require a hard wear-resistant surface. It is called "chilled cast iron" and is produced by sudden cooling of the melt to form a hard zone.

The carbon is in form of iron carbide and its content varies from $3-4 \%$. The other elements are silicon $(0.5 \%)$, sulphur $(0.1 \%)$, phosphorus $(0.1 \%)$ and manganese $(0.8 \%)$. It is used to make crusher jaws of rock-cutting machines, metal and paper rollers, ball milling plants, etc.

Grey cast iron also contains 3-4\% C, but as graphite; other elements are silicon (2-3\%), sulphur $(0.08 \%)$, phosphorus $(0.15 \%)$, manganese $(0.8 \%)$. It is less brittle and more machinable than white cast iron, and is used for making machine bases, engine blocks, brackets, pulleys, gears, etc.

\subsection{Malleable cast iron}

Malleable cast iron is produced by giving the white cast iron a modifying heat treatment involving slow heating for long duration (annealing). It is fairly ductile with $4-14 \%$ elongation (hence it is also called "ductile iron"), capable of withstanding suddenly applied stress, corrosion resistant, strong, tough and machinable.

Carbon content in the form of iron carbide varies from $2.5-3.0 \%$, silicon $0.5-1.1 \%$, sulphur 0.10 $0.15 \%$, Phosphorus up to $0.1 \%$ and manganese $0.4 \%$. It is used to make transmission line hardware, water fittings, tools, conveyor links, etc.

\subsection{High duty cast iron}

High duty cast irons are stronger than grey cast iron in which much of the carbon is originally in the form of coarse flakes. These contain metals such as nickel, chromium, copper and also some other substances such as calcium silicide, cerium or magnesium may also be added. Its carbon content may vary from $2.5-3.5 \%$, silicon from $1.5-2.5 \%$, sulphur $0.02-0.1 \%$, phosphorus from $0.02-2.0 \%$ and its manganese content is around $0.8 \%$.

If calcium silicate is added to the liquid metal, graphite is transformed into fine flakes, and the cast iron is known as "mechanite cast iron". It is used to make products like gears, fly wheels etc., where strength is needed. If cerium and/or magnesium is added to the liquid metal, then the graphite is transformed to fine spheroidal form, and the cast iron is called "spheroidal graphitic cast iron or SG cast iron". The metal may be annealed before use, in which case the elongation increases by up to $20 \%$, and the product is called "ductile iron". It is used for making crank shafts, metal working rolls and for other works where high strength is needed.

\subsection{Wrought iron}

Wrought iron is defined by the American Society for Testing Materials (ASTM) as "a ferrous material, aggregated from a solidifying mass of pasty. Crystalline particles of highly refined metallic iron, with which, without subsequent fusion, is incorporated a minutely and uniformly distributed quantity of slag".

The main distinguishing characteristics are:

- Carbon is practically absent, i.e. it is an almost pure form of pig iron;

- It must contain some slag (1-3\%) ferrous silicate), which is the result of oxidizing reactions of refining, and which is uniformly distributed as minute threads imparting a fibrous structure (cf. crystalline structure of steel). Because of the absence of carbon, it is highly malleable and it can be shaped into useful articles by reheating and forging. Wrought iron was the product in use since the prehistoric age till the advent of the age of steel in 1856.

The furnace used was small and the heat applied was low - up to $1500{ }^{\circ} \mathrm{C}$ or so, i.e., less than the melting point of iron $\left(1800{ }^{\circ} \mathrm{C}\right)$. The technology was somewhat improved by H. Court in 1784 .

But even then, it was limited by the small size of the furnace (called "puddling furnace") and low temperature that could heat the mixture of ore and flux to a semisolid mass, and it required constant manual stirring for the oxidizing reactions to take place.

As, unlike in steel-making, the metal and the slag were not in molten state, they could not be separated and thus the slag got thoroughly impregnated in the metal. By squeezing and rolling the semisolid mixture, the content of slag could, at best, be reduced, but not totally removed. This is how characteristic fibrous structure was formed in wrought iron.

After the advent of steel, the highly labourintensive nature of the technology of making wrought iron and its low productivity resulted in fast obsolescence of this primitive product, but, even then, it continued to find some use where corrosion and shock-resistance were important criteria.

\subsection{Directly reduced iron}

Directly reduced iron (solid reduction), when in lump form, is called "sponge iron"; when in briquette 
form, called "hot briquetted iron or HBI"; and when in liquid form, it is called simply "hot metal" [13]. All these products are feedstock for steel-making in electric arc furnaces.

These are produced by non-blast furnace methods, and the reduction of iron ore takes place either in solid state or in liquid phase. The technology was first tried on pilot scale in the 1920s, and the trials were intensified after 1939. At least, 32 processes have been investigated since 1939. The relatively more important and currently relevant processes can be grouped under the following generic names:

$\begin{array}{ll}\text { - } & \text { Direct Reduction (DR); } \\ \text { - } & \text { Smelting Reduction (SM); } \\ \text { - } & \text { Plasmasmelt. }\end{array}$

\subsection{Iron carbide $\left(\mathrm{Fe}_{3} \mathrm{C}\right)$}

$\mathrm{Fe}_{3} \mathrm{C}$ is a reduced iron oxide with $5-6 \%$ chemically fixed carbon. It is a direct feed for steelmaking and it provides added energy through the inbuilt carbon content. It is produced in a fluidized bed reactor through a gas-solids reaction. Preheated iron oxide fines (0.1-1.0 mm size) are supported in an upward stream of gas composed of $\mathrm{CO}, \mathrm{CO}_{2}, \mathrm{H}_{2}, \mathrm{CH}_{4}$ and water vapour at a temperature of 550-600 ${ }^{\circ} \mathrm{C}$ which is lower than the one required by sponge iron [13].

Hydrogen reduces iron oxide to iron which reacts with carbonaceous gases to produce $\mathrm{Fe}_{3} \mathrm{C}$. The viability of the technology depends on a steady and assured supply of natural gas. Its commercial viability has not been established in India.

\subsection{Steel}

Iron and steel scrap, sponge iron, hot metallic iron and pig iron - all are processed to obtain the end product steel (also called "plain carbon steel"). Steel is essentially a refined alloy of iron and carbon with carbon content lower than in pig iron - generally varying from $0.01-1.7 \%$, but it may go up to $2 \%$ [14].

Total absence of carbon would make it very soft and unusable for most of the purposes. Steel-making is, therefore, nothing but the removal, by combustion, of the carbon contained in the iron.

As a result, the structure of the metal becomes more resilient, more flexible, stronger and better workable than iron. Besides carbon, sulphur and phosphorus are also removed by oxidation, a little manganese and silicon are added to improve the mechanical properties of steel (if too much of these are added, then the steel would be called "alloy steel").

For removing the impurities, coke and flux are charged along with the pig iron. Some iron ore is also added to the charge for providing oxygen for reaction with the fuel for heat generation and better operational control by which the impurities (including those in the fuel) are removed in the form of slag.

\section{Conclusions}

Hematite, an iron oxide, can be found in large deposits; it provides important estimated reserves, most in mined iron.

The two possibilities of using hematite are as iron ore and industrial mineral.

Hematite is useful in different forms and applications.

Now, the production of hematite is increasing due to its properties:

- Resistant to corrosion;

- Refractarity;

- Medium hardness;

- High degree of oxidation, so it is difficult to separate in the constitutive elements.

\section{References}

[1]. Ralls K. M., Courtney T. H., Wulff J., Introduction to Materials Science and Engineering, John Wiley \& Sons, New York, 1976.

[2]. Smith W. F., Hashemi J., Principles of Materials Sience and Engineering, $4^{\text {th }}$ edition, McGraw-Hill Book Company, New York, 2006.

[3]. ***, ASM Handbook, vol. 9, Metallography and Microstructures, ASM International, Materials Park, OH, 2004.

[4]. Glicksman M., Diffusion in Solids, Wiley-Interscience, New York, 2000.

[5]. Dowling N. E., Mechanical Behavior of Materials, $2^{\text {nd }}$ edition, Prentice Hall PTR, Paramus, NJ, 1998.

[6]. McClintock F. A., Argon A. S., Mechanical Behavior of Materials, Addison-Wesley Publishing Co., Reading, MA, 1966, Reprinted by CBLS Publishers, Marietta, OH, 1993.

[7]. Jankovic A., Iron Ore-Mineralogy, Processing and Environmental Sustainability, p. 251-282, 2015.

[8]. Tolod K. R., Hernandez S., Quadrelli E. A., Russo N., Studies in Surface Science and Catalysis, vol. 178, p. 65-84, 2019.

[9]. Pawar R. C., Lee C. S., Heterogeneous NanocompositePhotocatalysis for Water Purification, p. 43-96, 2015.

[10]. Wagh A. S., Chemically Bonded Phosphate Ceramics (Second Edition), Twenty-First Century Materials with Diverse Applications, p. 157-164, 2016.

[11]. Koy J., Ladebeck J., Hill J. R., Studies in Surface Science and Catalysis, vol. 119, p. 479-484, 1998.

[12]. Chen L., Xiong D., Progress in Filtration and Separation, p. 287-324, 2015.

[13]. Clout J. M. F., Manuel J. R., Iron Ore-Mineralogy, Processing and Environmental Sustainability, p. 45-84, 2015.

[14]. Dai H. X. et al., Process Mineralogy of an Oolitic Hematite Ore and its Implications for Mineral Processing, Advanced Materials Research, vol. 567, p. 131-134, 2012. 